\title{
Health related vulnerabilities and enabling institutions to facilitate responses to climate change in East Africa
}

\author{
Andrew K. Githeko \\ Kenya Medical Research Institute, Centre for Global Health Research, Climate and Human Health Research Unit, P.O. Box 1578 Busia Road, Kisumu.40100 \\ * Corresponding author: Andrew K. Githeko, githeko@yahoo.com,ORCID \# 0000-0003-3039-6248
}

\begin{abstract}
It is now accepted that climate change is having and will continue to have a direct or an indirect impact on human health and in most cases, it will be negative. In this review the links between climate and climate sensitive diseases is established. The review goes further to examine what it will take for health research institutions to address adaptation to climate change, while reducing institutional vulnerability and improving their response to climate change. Evidence has emerged that range expansion of climate sensitive diseases such as malaria, meningitis, Rift Valley Fever, chikungunya and cryptosporidium is occurring and this will increase pressure on the health systems across Africa. Climate related risks in health will require a proactive approach in order to prevent rather than manage health disasters. Diseases epidemic predictive models will enable early detection of the risks and intervention. The health system is dependent on several national and foreign partners forming a critical network. If these networks malfunction then the health systems will be highly susceptible to failure. Governance and leadership of the institutions will determine the rate of adaption to climate change. There is need to strengthen research institutions in Africa because they can run long term programs addressing climate change. Furthermore these institutions must expand their research agenda to include a multidisciplinary approach to solving problems. A closer collaboration between departments of meteorology, remote sensing and mapping and medical research institutions is now more urgent than ever. Development partners and national governments must invest in infrastructure that will enable adaptation with the aim of increasing the institutional capacity to cope and minimize the potential impacts of climate driven diseases.
\end{abstract}

Keywords: Climate change human health zoonosis institution vulnerability adaptation

\section{INTRODUCTION}

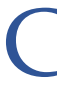
limate change will have a direct and indirect

impact on human health and well-being through different pathways. The frequency and intensity of extreme events associated with negative impacts is increasing and this trend will continue 1 .

Institutions are organizations with a formal governance structure that are instituted through a legal framework to carry out specific mandates.

African health research institutions will need to develop adaptation options to reduce the vulnerability and impacts. These public owned institutions and in partnership with civil society institutions will need to carry out an analysis of their strengths, weaknesses, opportunities and threats that may limit or promote the adaptation process. The threats from climate change will range from relatively benign diseases outbreaks to complex multi-disease epidemics that will be difficult to deal with. African populations expect that their research institutions will develop, test and deploy strategies to detect threats and prevent them. This paper intends to identify infectious diseases and other health conditions that are climate sensitive and that show clear seasonality. Thereafter insritutional research capacity fo adaptation research is explored. Lessons are derived from previous regional climate and health research projects. 


\section{Climate and health analytical framework}

Climate change is an evolving process that is expected to intensify Many infectious and non-infectious diseases and health conditions have different sensitivities to climate. Indeed the distribution of disease in time and space is a function to climate. Climate change which is a change in the mean climate state will have a direct impact on diseases spatial temporal distribution. Climate change will effect diseases range expansion and contraction. Climate variability will affect the transmission intensity in time and space and this includes the evolution of epidemics 2. Climate change may facilitate the emergence and reemergence of new and old infections 3 . In general climate change has a large scale effect in diseases distribution and incidence affecting large populations that can easily overwhelm health services in a country. Besides a change in spatial-temporal changes in disease distribution, a change in the frequency of outbreaks and epidemics can be expected. In addition spontaneous and multiple diseases epidemic may occur with severe consequences in the health system. Health research institutions will need to address the challenges of the new threats arising from climate change. These include tools and strategies for anticipating and minimizing risks. Such tools include early warning systems and mapping of risk in space and time. They could also include ways of targeting interventions to population that are vulnerable.

In the first part of this review an exploratory literature search has been carried out to determine if there is any evidence of the expected changes in diseases epidemiology under climate change.

Some of the major infectious and non-infectious diseases and how they are linked to climate and weather are reviewed. The limitations of the response of these institutions in reducing the impacts to climate change in health is explored.

\section{Health related vulnerabilities \\ Vector-borne, water-borne, air-borne, food-borne infections}

Infectious diseases include simple or complex life cycles that have many environmental determinants including climate. Each element of the life cycle has its degree of sensitivity to meteorological parameters and interaction with other environmental attributes such as topography, hydrology, land use and land cover. The meteorological parameters modulate the seasonality of the diseases and their distribution in space while some geographic features such as hydrology and topography may restrict the distribution of the diseases only in space. Climate change is expected to be associated with changes in some infectious diseases distribution in space while climate variability will affect the intensity of disease transmission in time. It is critical to assess the potential risk of epidemiological changes associated with climate change in preparation to counter the emerging public health threats whose impacts can be devastating. The risks are higher when the transmission range expands in areas where human population have low immunity and where the public health sector is unprepared to prevent and even treat the diseases. Already the epidemiology and impacts of the climate sensitive diseases has been observed in Africa and elsewhere in the world in infectious diseases such as malaria, meningitis, cholera, arbovirus infections and diarrhoea.

\section{Malaria}

Malaria is the most important infectious and vector borne disease in Africa. It is estimated that $74 \%$ of the population in Africa live in highly endemic areas for the disease and $19 \%$ in endemic prone areas $\underline{4}$. Most of the epidemics occur in the highlands and desert fringes and are driven by anomalous temperatures and rainfall 5. Many countries in Eastern Africa for example Kenya, Tanzania, Uganda, Eritrea, Burundi, Rwanda and Ethiopia have suffered from these epidemics. During these epidemics the disease incidence can increase 4 -8-fold and mortality by as

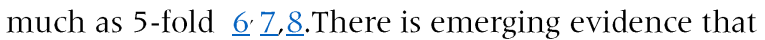
malaria is spreading to higher altitudes in East Africa 9 and to new highland areas that were previously free of the disease 10 . Warming occurring at the rate of $0.21^{\circ} \mathrm{C}$ per decade $\underline{3}$ in western Kenya has been associated with permissive conditions for increased malaria transmission 11. Recently malaria control activities across Africa have reduced the number of infections by as much as $50 \% \underline{12}$. While this is a positive development it will be accompanied by reduced exposure to the disease and subsequent reduction of the development of immunity resulting in increased vulnerability to severe disease unless the control efforts are sustained $\underline{13}$. Low immunity and increased climate driven risk would reverse the gains made in the control of the disease.

\section{Rift Valley Fever}

Rift Valley Fever (RVF) is a zoonotic disease that mainly affects livestock but is also infectious to humans. The disease represents a serious human and 
animal health threat and an economic burden. The pathogenic agent is a member of the genus Phlebovirus and family Bunyaviridae virus that cause haemorrhagic fevers. The disease is widespread in Africa and extending from Egypt to South Africa 14.

The primary vectors of the virus are Aedes mosquitoes while Culex, Mansonia and Anopheles species are also major vectors. The pioneer vector species in a habitat is the Aedes and within an ecological succession sequence is anopheles, followed by culex and finally Mansonia species. This virus can also be transmitted by aerosols of viremic blood during haemorrhage and by contact with infected animal and consumption of milk from infected animals. A devastating outbreak in Egypt in 1977-79 was associated with more than 200,000 human infections and 600 deaths and losses in livestock $>\$ 100 \mathrm{M}$ at that time 15 . More recently (1997-1998) a RVF outbreak occurred in eastern Africa affecting Kenya, Tanzania, and Somalia resulting in an estimated 27,500 human cases, and about 170 deaths $\underline{16}$.

Rift Valley Fever epidemics are associated with a sudden increase of Aedes mosquitoes caused by extensive flooding 17 . The virus survives the dry season in the drought resistant eggs of the Aedes mosquito species which then infects the larvae and finally the adult mosquito. The Culex and some Anopheles mosquitoes can then join the cycle and transmit the virus from one animal to the other. The mosquito infection rates can be very high as reported in Kenya where 5.9\% Anopheles squamosus, 30\% Aedes ochraceus, 42\% Aedes mcintoshi were infected $\underline{18 .}$

In Eastern Africa RFV epidemics have been associated with heavy flooding caused by the El Nino Southern Oscillation (ENSO) and the Indian Ocean Dipole 19.

Rift valley fever enzootics (epidemic in animals) have been expanding their range in Africa for the last several decades. For example in Kenya, incidence has increased from one province in the 1960s to six provinces by $2007 \underline{20}$. Enzootics have occurred when rainfall increases by over $50 \%$ of the normal amounts 20. Climate change is expected to increase extreme events such as floods and this is highly likely to increase the intensity and range of RVF enzootics. Livestock vaccination is currently in use in Kenya 21. however the vaccination is not licenced for human use.

East Africa Science 2021 | Volume 3 | Issue 1

\section{Yellow Fever}

Yellow Fever is caused by a flavivirus (family Flaviviridae) transmitted by the Aedes aegypti mosquito. The disease has two transmission cycles one occurring in urban areas and the other in the jungle (Sylvatic). The urban type is transmitted from man to man by the Ae. aegypti mosquito while in the jungle transmission occurs between monkeys and is transmitted by other Aedes species such as Ae. simpsoni and Ae. africanus. The severe form of the disease has a fatality rate of ranging from 15 to over $50 \%$ (CDC 2007).

Thirty-two African countries are now considered at risk of Yellow fever, with a total population of 610 million people, among which more than 219 million live in urban settings 22 . The disease occurs in epidemic forms particularly in Central and West Africa. Unpublished reports indicate that in 2008 Africa saw 13 Yellow fever outbreaks compared to the average of 2-5 outbreaks per year. The possible causes of the outbreaks range from lack of vaccination, accelerated urbanization and climate change. While Yellow fever has largely been controlled using vaccines, significant risks exist in unvaccinated populations. Furthermore climate change is likely to expand the range of the vectors while uncontrolled urbanization will increase the availability of breeding habitats for Ae. aegypti. Africa accounts for $90 \%$ of global Yellow fever cases 23. The heterogeneity of Yellow fever spatial-temporal distribution in Africa can be largely explained by temperature suitability of the vectors and the virus in addition to rainfall 23. This suggests that climate change and variability will affect the epidemiology of the disease 24 .

\section{West Nile Fever}

West Nile Fever (WNV) virus, which was first isolated in Uganda in 193725 is widely spread in Africa and it belongs to the genus Flavivirus. The virus mainly affects birds and equines and occasionally humans. In Africa horses are at a particularly high risk of the infection. The virus which was first isolated from Uganda in a human case has traditionally caused mild febrile illness in the past. However since the 1990s a more severe form of the disease was observed in Algeria, Morocco and Tunisia 26. Unlike RVF, WNF is mainly transmitted by culex species that primarily feed on birds. Human are considered a dead end host because they are highly unlikely to infect the mosquito vectors. The major vector of WNFV is Culex pipiens, however because of vector species succession, there could be several bridging vectors such as $C X$. 
antennatus and $C X$. univittatus have been implicated 27.

\section{Chikungunya}

Chikungunya (CHKV) is a viral disease caused by an alphavirus genus and belonging to the family togaviridae. It was first discovered in Tanzania in 1952 and causes symptoms similar to dengue fever 28 . The virus occurs in Africa with a wider distribution in the Eastern Africa and it is transmitted by the Aedes aegypti and Aedes albopictus mosquitoes. Although the disease has had low prevalence for a number of decades, recent outbreaks in Democratic Republic of Congo in 1999-2000 and Gabon in 2007 have caused concern. A more recent outbreak (2011) was reported in the Congo DR involving at least 8,000 people 29. It has been shown that the virus has mutated 30 and it's now able to infect Aedes albopictus and cause severe disease and mortality while in the past the virus was only transmitted by Ae. aegypti and caused mild to acute disease symptoms. In 2004 serological studies indicate that the prevalence of antibodies to CHKV in western Kenya was $60 \%$ and at the Kenyan coast $24 \%$ suggesting that there was active viral transmission 31 . In 2005-06 an outbreak in La Re-union Island the Indian Ocean involved 244,000 people and with severe clinical cases 32. The new vector Aedes albopictus in Africa which is originally from Asia is spreading fast on the continent. In Brazil it has been found that arbovirus infections transmitted by Ae. aegypti correlate with precipitation and temperature 33 thus climate variability and change is expected to affect Chikungunya transmission.

\section{Dengue}

The Dengue (DENV) causing virus belongs to the genus flavivirus and family flavivaridae. The disease is endemic in 110 countries in the world. The main vector is Ae. aegypti but Ae. albopictus is an important vector. Dengue has four closely related viruses referred to as DENV 1, 2, 3 and 4. The disease has two forms these being dengue fever (DF) and dengue haemorrhagic fever (DHF) with the former having febrile illness and the latter being severe and associated with mortality. During the period 1960-2010 a total of 22 countries in Africa reported sporadic cases of outbreaks of dengue and in the 12 other countries dengue was reported in travellers who had visited the areas 34 . Dengue has similar symptoms to malaria and is most likely misdiagnosed and under reported in Africa. As many as $70 \%$ of fevers clinically treated for malaria in Africa are not attributable to the disease but may be caused by flavivirus 17 . Dengue is mainly an urban disease and in some countries it has been associated with both excessive rainfall and drought. During droughts, Ae. aegypti breeds prolifically in water storage containers and during heavy and prolonged rainfall in discarded water containers 17 . Dengue infections exhibit seasonality often associated with rainfall and temperature suggesting that the disease is climate sensitive 35,36 .

In general rainfall increases vector abundance, while temperature shortens the vector and virus development period and increases their blood feeding frequency 37 (With regard to the parasites and viruses temperature reduces the extrinsic incubation period subsequently increasing the vector's infectious life. In combination the climatic factors increase disease transmission.

\section{Water-borne/food-borne diseases}

Many of the waterborne diseases such as cholera, and typhoid are also food borne diseases. However cholera, typhoid fever and hepatitis $\mathrm{A}$ are considered as the major water-borne diseases. Cholera is caused by the bacterium Vibrio cholerae which is found in marine and freshwater ecosystems 38 .

Between 1970-79, 19.7\% of global cholera cases were reported from Africa and by 2005, 94.8\% of these cases came from Africa. However the absolute number of reported cases in Africa has not increased significantly between the two periods but the number of countries reporting the disease has increased 39, 40. Cholera has been associated with temperature and rainfall anomalies 41 . In Zanzibar it was shown through modelling that a $1{ }^{\circ} \mathrm{C}$ increase in temperature at 4 months lag resulted in a 2 -fold increase of cholera cases, and an increase of $200 \mathrm{~mm}$ of rainfall at 2 months lag resulted in a 1.6-fold increase of cholera cases $\underline{42}$. The disease has a complex physiochemical and biotic drivers that resonate with climate variability. These factors include salinity, iron content, phosphates, nitrates, organic matter, algae, zooplanktons and temperature $\underline{43}$. Cholera epidemics in East Africa have been associated with El Nino years 44. 45. In the Western Kenya Lake Victoria region several discreet waves of cholera outbreaks and epidemics occurred in 1971-72, 1980-84, 1992-93, 1997-1998 and 2008 periods associated with El Ninos 46. In Kenya severe epidemics occurred in 1982 and 1997-8 years with strong and very strong El Nino events. Rift Vallley Fever epidemics have been reported in 2018/9 in Mayotte $\underline{47}$. 


\section{Other enteric diseases}

Enteric diseases (shigellosis, typhoid fever and cryptosporidiosis) are driven by a combination of human and environmental factors including, poverty, water resource and climate $\underline{48}$. Shigella is a family of bacteria that infect humans through contaminated water and food. Of the several types, shigella dysenteriae can cause severe epidemics. The disease that mainly affects children under 5 years causes bloody diarrhoea and can be fatal if not treated. Lack of water leading to poor hygiene during droughts can increase the risk of Shigella 49 .

Typhoid fever is a bacterial disease, caused by Salmonella typhi and is transmitted through contaminated food and water. Highest incidence usually occurs where water supplies serving large populations are contaminated by faecal matter $\underline{50}$.

The estimated incidence of the disease in sub-Saharan Africa is 50 cases per 100,000 persons 51 . Floods in areas of poor sanitation can increase the risk of faecal contamination of public water supplies.

In Africa cryptosporidium is a diarrhoea disease caused by the Cryptosporidium parvum, and Cryptosporidium hominis which are protozoan parasites. These parasites infect both man and animals and are transmitted through contaminated drinking water. The disease exhibits seasonality with the peak incidence being observed in the rainy season. However increased incidence has been observed in the dry season most likely due to the use of the few available contaminated water sources 52. In sub-Saharan Africa the disease is most prevalent in children 6-12 years old. The prevalence of the diseases is $5-25 \%$ in the region.

The seasonality of diarrhoea diseases has a complex relationship to weather and climate. In some instances the infections may be driven by drought while in others rainfall may be the driving factor 53 . Diarrhoea incidence in Botswana is associated with La Nina conditions that are characterised by above normal rains $\underline{54}$.

\section{Non- infectious health conditions}

\section{Malnutrition and under-nutrition}

Malnutrition is a condition mainly seen in children that do not consume a balance diet and leads to high risk of mortality, lowered resistance to infection such as diarrhoea and respiratory diseases, retarded physical and mental growths. A balanced diet should include proteins, carbohydrates and micronutrients such as vitamins and mineral. The World Health Organizarion (WHO)regards hunger and malnutrition as the gravest threat to public health, and climate change threatens to further destabilize already fragile food-production systems 55 . In the year 2000, 32\% of children fewer less than 5 years of age in-sub-Saharan Africa suffered various degrees of malnutrition $\underline{56}$ though this proportion has reduced in some countries notably Senegal and Uganda 57. Coupled with high fertility rates and shrinking arable land, high food prices and political instability, climate change induced droughts and reduced agricultural productivity will exacerbate the situation 58 .

While malnutrition refers to the quality of food, under-nutrition refers to the quantity consumed. Under-nutrition leads to wasting, underweight and stunting 59. Under-nutrition has been strongly associated, with shorter adult height, less schooling, reduced economic productivity, and for women, lower offspring birth weight $\underline{60}$.

\section{Heat waves and heat stress}

According to the World Meteorological Organization definition, a heat wave is when the daily maximum temperature of more than five consecutive days exceeds the average maximum temperature by $5^{\circ} \mathrm{C}$ degrees the normal period being 1961-1990 17 . Excessive heat and high humidity are associated with heat waves. The most vulnerable are young children, the elderly and those in poor health. Heat waves cause heat oedema, heat rash, heat crump, syncope, stroke, heart attacks and death 61 . While heat waves have occurred in the United States, Europe Australia and parts of Asia, no documented events have been reported from Africa. However in Burkina Faso the mean monthly temperature was significantly related to mortality in old ages and cardiovascular mortality varied by season, with higher mortality rates occurring in the hot dry season 62 .

\section{Air-borne diseases}

\section{Meningococcal meningitis (MC)}

Meningitis is an air-borne disease caused by the bacteria Neisseria meningitides. The disease occurs in the meningitis belt (Senegal -Ethiopia) which is defined as areas of West Africa limited mainly by rainfall, being bound by isohyets with the northern limit set at $300 \mathrm{~mm}$ rainfall per year and a southern limit at an $1,100 \mathrm{~mm}$ rainfall $\underline{63}$. Epidemics are associated with humidity below $30 \%$ for a period of five days. It has also been linked to the speed of the 
Harmattan winds 64. Currently the meningitis belt is expanding eastwards to Ethiopia and Uganda most likely due climate change 65 . During epidemics, the incidence can approach 1,000 per 100,000 , or $1 \%$ of the population 66. Improved MC vaccines are a promising investment that could substantially contribute to reduction of child meningitis mortality world-wide 67.

\section{Ecosystem vulnerability}

\section{Highlands}

The highlands were previously free of any major vector and water-borne diseases due to low temperatures. However in the recent past malaria epidemics have occurred in the highlands and an increase in temperature has been recorded. This trend is likely to continue leading to an increase of the human population at risk of severe disease and epidemics.

\section{Arid areas}

Arid areas are characterized by low rainfall and frequent droughts. Many of them are plains that are prone flooding during extreme events. Health threats range from famine to Rift Valley Fever and malaria epidemics.

\section{Aquatic systems}

Aquatic systems include lakes, oceans and rivers and they are directly affected by climate change. Extreme precipitation can cause flooding affecting human settlements and their health. Lakes and coastal areas can also be a reservoir for cholera. Strong El Ninos and flooding have been associated with large scale cholera epidemics 68. Many rapidly expanding cities are located in deltas that are at high risk of flooding as a consequence of sea level rise.

\section{Emmerging threats}

There is evidence of range expansion in malaria, Rift Valley Fever Chikungunya, cryptosporidium and meningitis. However there is evidence that current interventions such as the use of insecticide impregnated bed nets for malaria control, vaccines for RFV and meningitis have reduced the incidence of diseases and the occurrence of epidemics. However, some of the interventions such as insecticide impregnated bed nets may lose their efficacy in time while the climate risk is increasing. New viral strains could affect the efficacy of the meningitis vaccines.

\section{Climate change and variability impacts}

Climate change includes the change in the mean ambient temperature and also the departure from the mean. In Kenya for example the rate of change in the mean temperature has been $0.2^{\circ} \mathrm{C} /$ decade. This change has led to the increasing the suitability of malaria transmission in the highlands.

Climate variability refers to the departure of the ambient temperature from the mean value and this change can lead to diseases epidemics. For example during the 1997/8 El Nino event a temperature of $5.9^{\circ} \mathrm{C}$ above normal was observed in western Kenya and this was associated with the malaria and cholera epidemics in East Africa.

Extreme dry conditions and low humidity have been associated with meningitis epidemics in the Sahel region.

\section{Social economic vulnerability: poverty and culture}

Poverty leads to lack of access to information and other basic human needs including access to health care, safe drinking water and nutrition. A significant proportion of human populations in Africa lives in poverty and in environments referred to as pathogenic landscapes. These populations live in areas that have poor communication and infrastructure and are thus hard to reach in times of climate disasters. These populations have very low access to safe drinking water and are thus highly vulnerable to waterborne disease. Food insecurity leads to severe malnutrition and under nutrition during drought and famine.

Certain cultures can increase the exposure of populations to diseases. These include behaviour and practices that can increase the risk of encounter with pathogens. For example drinking raw milk and blood by pastoralist communities can increase the risk of Rift Valley Fever following severe flooding. Failure to use latrines by some communities contaminates streams and rivers during the rainy season and this increases the risk of diarrheal diseases.

\section{Importance of public and civil institutions to facilitating adaptation}

\section{Institutional Vulnerability}

Institutions are human organizations created or developed to address specific activities geared towards the production of goods and services for the common good of society. In many cases they have a legal mandate, stated goals, performance targets and 
societal values. Their organizational structure and governance are geared to achieving these stated goals and performance targets. A Pressure-State-Response (PSR) framework is required to assess the performance of an institution given certain levels of demands or pressures $\underline{69}$ In order to provide an objective assessment of an institution a set of indicators are required. In the health sector there are several players that provide policy, knowledge, services, interventions, training and financial support. Linkages between these players and their institutions are critical to the performance of the sectors and in particular their response to pressures and demands such as would be caused by climate change. Pressure from climate change is characterized by uncertainties and increasing risks arising from the dynamic state of the climate. Such a state increases the institutions vulnerability to external and internal shocks and failure to meet the set targets of minimizing disease incidence and poor health.

A number of factors can affect the performance of an individual institution. These include governance, human capacity, capital, linkages and relationships with partners and end users. A failure in any of these attributes can reduce the capacity of an institution in meeting its performance targets and in particular under the pressure of climate change. For example can health institutions prevent instead of manage climate related health risks? Are the institutions proactive or reactive?

\section{FIGURE 1: Research dema under and supply under climate stress}

\section{Research demand and supply}

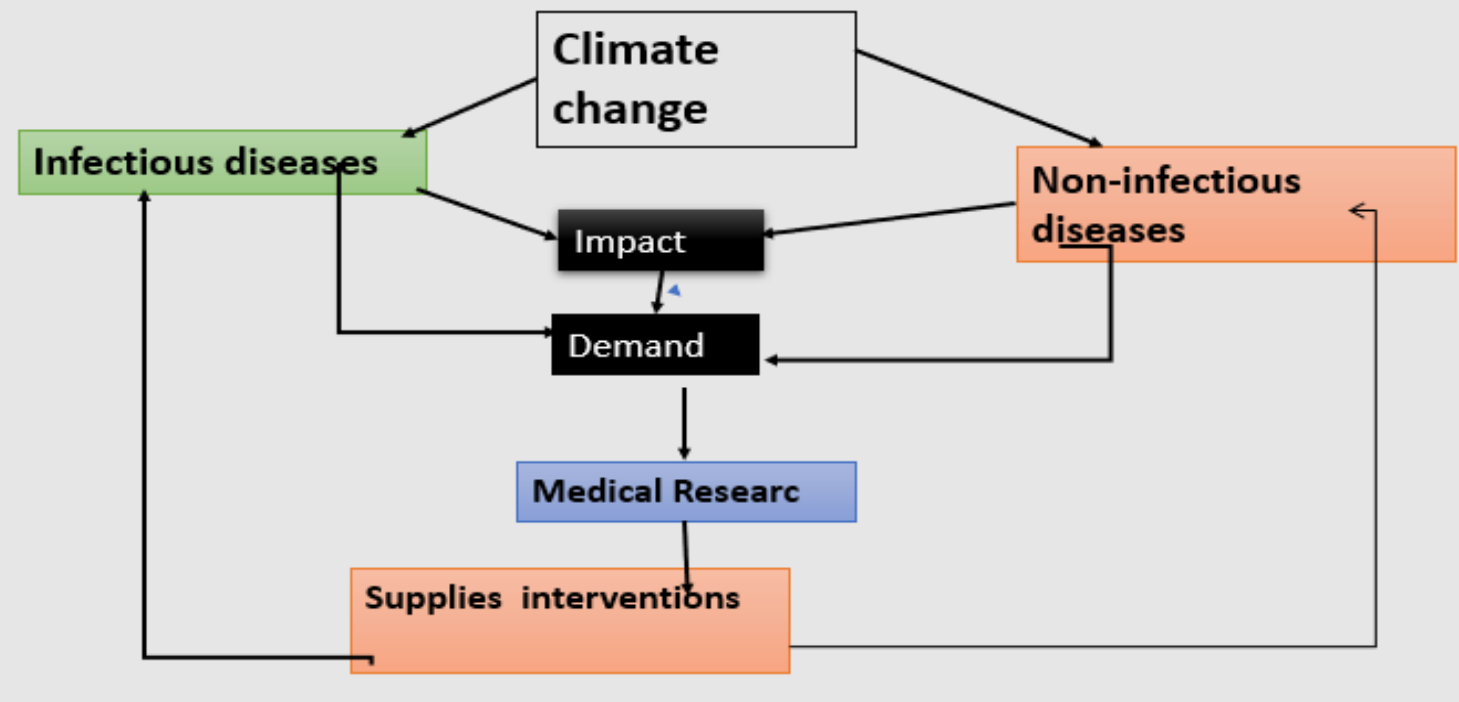

\section{Stakeholder engagement and institutional vulnerability}

There are a number stakeholders involved in adaptation to climate change and these include knowledge generating institutions, policy makers, implementers of policy and supporters of policy implementation (development partners). Policy may evolve from a number of events such as new or emerging knowledge, a political or development vision or a need to address a public need e.g. public health. These stakeholders represent a supply chain for the development of policy and their implementation. However in some cases there is a disconnect in the supply chain and some stakeholders are not aware of what the others are doing. For example a university may make a breakthrough in technology but the technology may remain in academia. In some other cases good technologies may be developed however in 
the absence of donor support this technology may never see the light of the day. These types of disconnections among stakeholders represent substantial institutional vulnerability. In this respect institutions are not able to respond to their stated mandates due to failures or weakness in the adaptation process supply chain. For example while the malaria early epidemic prediction model $\underline{70}$ was published in 2001 its testing and validation did not take place until 2007 when funds become available from the International Development and Research Centre (IDRC)

funded Climate Change Adaptation in Africa Program (CCAA). Local research institutions were unable to carry out the validation despite the fact that the skills existed in the region.

In the next section, attributes that could increase institutional vulnerability are addressed.

\section{Health Institutions}

The role of governments in the health sector is to provide disease prevention, maternal and child healthcare, and curative services. The great majority of illnesses are caused by infectious diseases and which in many cases are climate sensitive. Climate change is increasing the risk of infectious diseases and epidemics associated with these diseases and there is a need to develop strategies for addressing these new threats. In addition there are emerging and re-emerging diseases that may be associated with climate and environmental change. Research institutions are expected to address the new health threats and develop preventative strategies and reduce the public health impacts. Weak public health institutions are highly vulnerable to the impacts of climate change as they may be unable to cope with large numbers of cases involved in disease outbreaks, epidemics and new populations are at risk. There is a need for the health institutions to address the threat of climate change on health in Africa. Many of these institutions are fragile and may not be able to cope with this emerging threat that is expected to increase.

Health institutions in Africa have the capacity to use climate information to identify climate associated risks particularly in infectious diseases and other direct impacts of extreme weather events. This has led to disaster prevention rather than disaster management. The health authorities have recognized the need for early warning systems in epidemic prevention but until recently these systems were not developed. Furthermore it is critical to use climate data and disease surveillance systems to identify populations at risk from diseases whose transmission range is increasing or where the environments are becoming receptive to transmission.

\section{Research Institutions}

In Africa medical research is carried out by national medical research institutes, universities nongovernmental organizations and foreign institutions. Each of these institutions has its own mandates and research priorities which may or may not correspond to the national research priorities. Where they exist, the national research institutes have the mandate to address existing, emerging and re-emerging health concerns. However, many of these institutions are to a large extent dependent on external supports to carry out their research and in many cases research focus is dependent upon the priorities of the funding agency 71. In addition research may place priority on health conditions with the greatest burden and urgency such as Aquired Immuno-deficiency Syndrom (AIDS) / Human Immunodeficiency Virus (HIV), Corona Virus Disease (COVID-19) and Tuberculosis (TB)

Even in the absence of climate change Africa has a great disease burden driven by the tropical climate and low socioeconomic development. Research institutions are engaged with improving the control of diseases that have existed for millennia. While some countries have dedicated medical research institutes others do not have them and mainly rely on academic institutions to carry out health research. In other instances research is carried out by foreign entities that focus on very specific research programs.

Climate change increases the burden of infectious and non-infectious diseases. Some of the diseases such as viral infections require specialized laboratories to handle the often highly infectious pathogens. Very few of these facilities exist in Africa and quite often foreign assistance is sought in diagnostics of such infections. In additional there are few active surveillance programs to track the incidence of transmission in the interepidemic and enzootic periods.

Climate variability is largely responsible for large scale epidemics of malaria, Rift Valley Fever, chikungunya, dengue fever, cholera and meningitis. The capacity to accurately predict the risk of these epidemics is critical to epidemic prevention. Until recently climate based early warning systems were not developed and quite often health authorities were caught unaware, resulting in ineffective and late response and subsequently high morbidity and mortality. Recently 
early malaria epidemic prediction models have been developed and have been shown to have high positive predictive values, sensitivity and specificity $\underline{7}$. In addition they have a lag of 2-4 months between the climate signals and the onset of the epidemic thus providing ample time for interventions and prevention. Similarly RVF epidemic can now be predicted with considerable accuracy using sea surface temperatures (S STs) in the Pacific and Indian Ocean. Research and development of climate based prediction models for meningitis is in progress.

Research institutions in Africa are often constrained by lack of funding, low capacity for research and retention of personnel. Climate change is putting pressure on health and there is need to undertake research projects that provide tools for climate risk management and indeed new strategies for immediate and long term disease control. For example swamp reclamation in many highlands regions has led to a significant increase in malaria transmission $\underline{72}$ by alteration of the microhabitat and microclimate. However, it has been shown that restoration of the swamps with Napier grass could reduce water temperature and reduce the breeding of malaria vectors by about $80 \% \underline{73}$.

In some instances there is a weak link between health providers and research institutions. Yet health providers collect vital health data that can indicate trends in climate sensitive diseases. Lack of strong linkages between the research institutions and their data generating partners weakens their capacity for a proactive management of climate related health risks. Historically health management information systems (HMIS) in Africa have been very poor with the exception of South Africa. Reasons for this state of affairs have been the lack of "data culture" very low data recording and storage capacity, poor diagnoses and low prioritization of morbidity data. Priority has been placed on recording births and deaths (DFID Health Resource Centre Eldis). Since the mid 1990s there has been some improvement on data management following the introduction of computers to the HMIS. This has greatly contributed to allocation of resources and improved management of the health systems. Whereas this data is useful in tracking disease trends, quite often there is a question of data quality for research purposes as quality assurance may be absent. In times of climate change and rapidly changing disease landscapes there is a great need to access high quality health data in the development of predictive models and their validation. In addition such data can identify new trends and emerging or remerging infections and other health conditions. It is time to change from a leisssez-faire approach to a proactive one. Decisions on preventative interventions of diseases are dependent on reliable data on diseases trends and climate data that indicate trends in the risk of a diseases outbreak. Predictive models are required for routine use in climate risk management but as of now even where models are available the health systems have not made use of them.

\section{Funding agencies (including development banks)}

It is a well-established fact that funding agencies determine the priority funding areas among the many health research needs which may reflect global or regional health concerns. In many cases funding agencies will depend on health statistics indicating the incidence of disease in prioritizing areas that need research. Significant changes in disease incidence may call the attention of funding agencies to determine the cause of the changes. This process will lead to attribution of the drivers of the incidence. Climate change is a slow process that may not cause dramatic increase in diseases incidence. However, climate variability may cause alarming epidemics that warrant concern by the whole health system and this could lead to funding research that attempts to solve the puzzle. This has been the traditional approach to funding medical research. It is important to recognize that range expansion of infectious diseases can occur quite rapidly once certain climatic thresholds have been exceeded. For example in the Central Kenya highlands malaria transmission took place after the annual mean temperature permanently exceed the $18^{\circ} \mathrm{C}$ threshold temperature for malaria transmission 74. This recent spread in malaria transmission has put an additional 4 million people at a risk. A similar process may be taking place in the expansion of the meningitis belt. Research institutions should be carrying out passive and active case surveillance to map out new areas that are at risk. In addition they should be monitoring changes in climate that will support the spread to disease. Failure to undertake these types of studies will leave populations exposed to risk of emerging and re-emerging infections. Thus research institutions that suffer from various forms of funding and technical and leadership shortfall will be vulnerable to climate change shocks.

IPCC reports have played a big role in showing the linkages between diseases and health conditions with climate change and variability. Nevertheless there has been dissent by a section of the scientific community, which has slowed down the response of funding agencies due to the uncertainty in attribution of the causes of epidemic such as malaria in the East African 
highlands. For example it has been reported 75 that the widespread increase in resistance of the malaria parasite to drugs and the decrease in vector control activities may be more likely driving forces behind the malaria resurgence in the western Kenya highlands. However other researchers attributed the evolution of epidemic to climate change $\underline{76}, \underline{77}$, with drug resistance and lack of vector control acting as secondary amplifying factors.

In recent years, new climate change funding mechanism has facilitated research on the impact of climate change on diseases. For example the Assessment of Impacts and Adaptation to Climate Change (AIACC) project was an outcome of the IPCC third assessment report funded projects on the impacts of climate sensitive malaria and cholera in the Lake Victoria Basin in East Africa. Thereafter, the Climate Change Adaptation in Africa (CCAA) supported the development, validation and transfer of the climate based early malaria epidemic prediction models.

There are indications that traditional funding agencies and new funding mechanism are beginning to address the impacts of climate change on health. For example funds from Google were made available to carry out research on Rift Valley Fever. (RFV) in Kenya. In the process it was discovered that other arbovirus co-exist with the RVF namely chikungunya, West Nile Fever and dengue fever in eastern Africa. Following the initial manifestations of global climate change on human health, United States government is in response to expanding the focus of its research and development activities to include an increased emphasis on understanding, predicting, and responding to climate change impacts $\underline{78}$ The National Institutes of Health (NIH) in the United States are perhaps the biggest funding agency for health related research. Nevertheless, these funding opportunities are extremely competitive and few African researchers have the capacity to access this funding and this raises another point in the vulnerability of African health research institutions.

The International Development and Research Centre (IDRC) of Canada and the British Department of International Development (DFID) founded a special funding model for adaptation in Africa by making funds available to the Climate Change Adaptation in Africa (CCAA) a program that was fully managed by Africans and African institutions. This model encouraged African research institutions to collaborate in solving common adaptation problems in several climate sensitive sectors. This model is unique and seems to have provided Africans with opportunities to make critical research and management decisions adding a sense of ownership to the process of adaptation.

Within the development banks domain, the World Bank is examining how public finance can catalyse climate action by piloting innovative ways to leverage both climate and development finance, such as combining resources and instruments to maximize synergies, exploring new opportunities to expand the scope for market mechanisms, and strengthening the capacity to facilitate access to resources and their effective use $\underline{79}$. In addition the bank has in a small step started funding health pilot projects through the Global Environmental Facility. The African Development Bank recognizes that health problems in Africa are integral to other development problems $\underline{80}$ It is hoped that the banks will in the near future invest in building capacity in climate related research in health.

United Nations Institutions, World Meteorological Organization (WMO), Intergevernmental Panel on Climate change (IPCC), World Health Organization (WHO), United Nations Environmental Program (UNEP) and United Nations Children Fund (UNICEF).

The United Nations (UN) agencies have been very instrumental in handling matters of climate change and building international consensus on the impacts of climate change and health.

The World Meteorological Organizations has the role of providing weather services and preventing weather related disasters. Moreover WMO has a leading role in monitoring global climate change and variability.

The IPCC reports have identified where there are gaps in knowledge that requires inputs from research. For example the Assessment of Impacts and Adaptation to Climate Change in Africa (AIACC) project was a spin off from the Third Assessment Report. The World Health Organization acknowledged that climate change will, particularly in Africa, have a negative impact on vulnerable populations. According to WHO areas with weak health infrastructure - mostly in developing countries - will be the least able to cope without assistance to prepare and respond $\underline{81}$. Many African countries- mainly in the sub-Saharan region fall in this category. Again this raises the institutional vulnerability of African health infrastructure on handling climate change impacts.

The United Nations Environmental Program (UNEP) has an important role in monitoring environmental 
changes including climate change and proposing interventions. In particular UNEP pays special attention to vulnerable ecosystem that will be affected by climate change.

According to UNICEF 2007 an estimated 9.2 million children worldwide under the age of five died from largely preventable causes among these malaria, diarrhoea and malnutrition, all climate sensitive diseases. A significant proportion of these children came from Africa. Weak and fragile health institutions in Africa will not be in a position to reverse this trend. Climate change will increase demand from these institutions.

\section{Non-Governmental Organizations (Local and International)}

Non-governmental organizations play a critical role in research and development in Africa. They play an important role on the development and deployment of adaptation strategies and in accessing research funding in a very competitive environment. Among the major players in health is the International Centre for Insect Physiology and Ecology (ICIPE) which has a focus on crop, animal, human and environmental health. The International Livestock Research Institute (ILRI) has a focus on animal health and has projects in several countries in Africa. Its research affects peoples livelihoods particularly pastoralists living in fragile ecosystems and who are very vulnerable to climate change and variability.

While the former are examples of international NGOs there are myriads of local NGO that are deeply embedded in communities across Africa and they play an important role in embedding adaptation strategies in rural and urban communities in Africa. Many of the local NGO are involved in distribution of insecticide impregnated bed nets for malaria control while others are involved in the provision of safe drinking water. Thus both international and local NGOs have an important role in the development of adaptation strategies and their deployment.

\section{Universities}

Universities play a dual role in training and research. It is the duty of universities to address the impacts of climate change and develop adaptation strategies. African universities must engage in research that can be translated into adaptation options. In the past universities have been referred to as "ivory towers" that were more concerned with academia rather than addressing practical solutions in society. Many of the African experts on climate change are based in national universities and being the most knowledgeable members of society they must lead in finding solution to adaptation in health and other climate sensitive sectors.

In recent times special funds have become available to climate change and higher education $\underline{82}$.

\section{Governments}

Health services are provided by governments and the private sectors but with the governments providing most of the services to the majority of the population. Planning of the capital and recurrent expenditure while dependent on the availability of funds must take into account trends in health care demands. The health of African populations is expected to improve as the economies improve. However climate change may reverse some of the gains made in population health. It should be noted that the health sector talks of interventions instead of adaptation. These could be short and long term interventions.

Governments have several mechanism and options in facilitating interventions. For example they are responsible for policy development and financing and coordinating intervention programs. Furthermore government can access special international funds for adaptation projects that aim at developing strategies to reduce or avoid the impacts of climate change. Governments are signatories to international agreements such as the Millennium Development Goals and which have a direct link to adaptation to climate change.

The ministries of health are responsible for interventions such as national malaria control programs and disease control by for example vaccination. Primary health programs in the ministries of health aim to prevent disease at the community levels through public health education, vaccination and enforcement of sanitation. These measures can for example significantly reduce the risk of cholera and other climate sensitive infectious diseases. The level of investment in the health sector will determine the degree of vulnerability of the populations to the impacts of climate change.

\section{Governance, research and capacity building}

\section{Leadership}

Leaders drive institutions to success or to peril. Leadership should be earned and not conferred. There are a number of leadership styles but three of them will suffice. The first type is transformational 
leadership that leads the institution to achieve its goals and missions by a positive transformation of the teams. The leader may completely change the attitude of the teams through a number of techniques and strategies. A second form of leadership is the transactional type where performers are rewarded and non-performers chided. The third type of leadership is the laissez-faire behaviour where a leader does not perform, that is, leadership absence. The leader abdicates responsibility, delays decisions, gives no feedback, and makes little or no effort to satisfy followers' needs $\underline{83}$.

Some leaders practice a mix of these forms and this could lead to uncertainties in the teams who may be unable to deal with the unpredictability of the leader. Institutions have a chain of leadership hierarchy whose dominant behaviour may draw its strength and direction from the prime leader.

In a research institution skills in project management are key to the success of the institution. The principle investigator must have the ability to write competitive grants, attract funding operationalize the grant and publish the results. This calls for intellectual and physical stamina that is not common. Obtaining such skills takes many years of practice and usually under a good mentor. Project management cannot practice a Laissez-faire behaviour but will need to practice a transformational and a transactional style.

To remain competitive institutions must have a high productivity of research results that are usually assessed through publications. The productivity of an individual can be determined though the internet based publication records. Even more important the general interest in ones work can be gleaned on the internet.

The prime leadership of an institution should exhibit unquestionable credibility given that research institutions received substantial amounts of funds which need to be accounted for. A high moral and ethical standard is required. Funding agency take a keen interest in the credibility of the institution and any weakness in this area could lead to high vulnerability to missed opportunities.

Visibility of an institution is of particular importance to its clients, that being the general public end-users and funding agencies. Highly successful but quiet institutions have received lesser attention than institutions that are more visible. Institutions must be seen to be proud of their achievements and they must never be seen to doubt their own products. They must embrace competition and its allied strategies.
Finally institution must remain highly relevant to their prime beneficiaries and these being the general public. There are instances where researchers have become the prime beneficiaries of a research institutions and this can lead to withdrawal of support by funding agencies.

\section{Internal and external power and politics}

In the functioning of institutions certain individuals or offices are mandated to perform defined roles and to execute decisions. These roles may include policy formulation, service provision and technical support. Appointments to these roles are dependent upon legal requirements, technical competence financial leverage and political affiliation. Much conflict can occur in the appointments to certain positions. For example an office requiring high technical competence may be occupied by a political appointee. Likewise the power hierarchy may be distorted by political affiliations. Offices with legal mandates may use this leverage to down-regulate technically competent subordinates and subjugate their role in the organization by denying them the means, for example financial support to perform their legitimate roles.

Organizations have internal and external power players that influence the decision making process such as policy formulation and implementation. The internal players include bureaucrats and technocrats while external players include policy advisors and even external technical advisors. Self-interest may dictate the decision making process and may also result in a power struggle within the institution and its partners. This situation can lead to poor implementation of policy, misdirection of resources and non-performance.

Such a scenario would cause the institution to become highly susceptible to failure under the pressures of climate change. For example superficially induced uncertainty about the cause of malaria epidemic can delay an early intervention. For example there are numerous assertions in literature that climate variability is not the key driver of malaria epidemics and by extension climate data cannot be used for early prediction of the epidemics. Such a scenario causes the responsible institutions to be highly vulnerable to inadequate or no responses to the health disasters. Likewise financial considerations may lead to the application of inappropriate interventions which leads to a loss of public confidence in the health institutions.

Key health intervention decisions are based on data. In particular climate and epidemiological data are very 
important when dealing with climate change risk management. Data can become a powerful political tool that can be used for institutional or personal gains. An institution that is dependent on external data sources is highly vulnerable to underperformance and low decision making capacity.

\section{Infrastructure and resource sharing}

Increased research and development in adaptation will demand an increase in research infrastructure which includes laboratories, office space, equipment and transport. In some cases there will be need to share the existing research facilities due to the interdisciplinary nature of response to climate change impacts and adaptation. For example regional remote sensing facilities have greater application in disease mapping. Ground mapping using Geographic Information System (GIS) and Global Positioning System (GPS) will be used to map disease risks and populations at risk. Spatial modelling of disease risk will relay on these technologies. While in the past there was very little interaction between medical scientists and the mapping community this will have to change in the future. In addition health and meteorologist will need to work together in climate data collection and analysis. The health community will be called upon to take a greater role in the meteorological data collection using electronic devices and automatic meteorological station.

In general investments in infrastructure will be required but also a greater partnership with existing specialized facilities. There will be a need for collaboration between local and regional institutions to make research cost effective.

Some key areas that will need research include, diagnostic tools, disease surveillance, disease risk mapping, diseases range expansion and contraction (meningitis, malaria dengue etc.), active and passive diseases surveillance in vulnerable ecosystems and epidemic risk potential.

\section{Model development}

Models are critical tools for risk assessment as they can extrapolate temporal and spatial risks thus providing sufficient time for response. Three types of models are relevant to health. Many infectious diseases such as malaria, cholera, meningitis and Rift Valley Fever are climate sensitive prone to large scale epidemics that can affect significant proportions of human populations. In many cases morbidity and mortality can increase several-fold. The rate of transmission in some cases has an exponential trend which makes interventions very difficult and the disease spreads rapidly. Progress has been made in the use of climate information in identifying meteorological threshold that represent epidemic risks. This type of information can be used to develop early warning systems (EWS) with high sensitivity, specificity and positive predictive power. In the case of malaria the climate based early epidemic prediction model has a lead time of 2-4 months thus providing ample time and opportunity to intervene and prevent an

epidemic.

\section{FIGURE 1: Evolution and prediction of malaria epidemic}

Temperature anomaly $3^{\circ} \mathrm{C}$

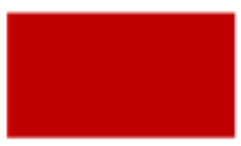

First

climate

signal

SEP_97
Rainfall
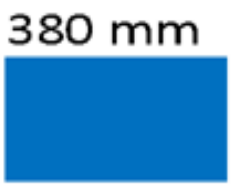

Epidemic

risk =

$60 \%$
Malaria case anomaly (\%) $\begin{array}{lll}579.9 & 656.9 & 795.1\end{array}$

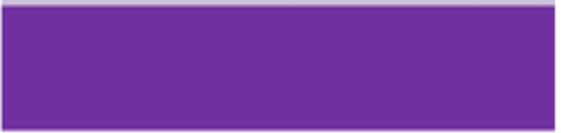

Malaria epidemic

JAN_98FEB

MAR 
Previously epidemics could only be detected when they were in progress and they could not be prevented. Models for other diseases such as cholera, Rift Valley Fever and meningitis have not been well developed.

Infectious diseases are spreading from their endemic areas to new areas due to climate change. Malaria in particular is spreading to highlands areas where it did not exist before. In Kenya the disease has spread from low altitudes to higher altitudes in central Kenya highlands putting about 4 million people at risk 2 . Spatial models need to be developed to identify areas that risk of disease spread and also the rate of spread.

Adaptation in the agriculture and water sectors will involve irrigation and construction of dams and water reservoirs. This will have an impact on water related diseases such as malaria and schistosomiasis. Models need to be developed to assess the risk of establishment of these diseases in new areas.

The risk of disease transmission intensity in space is not uniform and it has been shown to vary depending on some geographic parameters such as topography and hydrology. In some cases transmission has been shown to be clustered while in other cases it is random. Such characteristics have implications for intervention strategies. Spatial modelling can make major contributions to guide intervention strategies $\underline{84}$.

\section{Building partnerships}

Climate change will call for building new institutional and sectorial partnerships to bring in effective adaptations that are cost effective. The traditional sectorial funding will need to change. For example there is very little interaction between the irrigation sector and the health sector or between the water and the health sector. Irrigation can be a major source of vector borne diseases such as malaria. House modification by medical scientists in a rice irrigation scheme in western Kenya has been shown to reduce the risk of mosquito bites by $80 \% \underline{85}$. Water conservation strategies using micro-dams in Ethiopia caused a significant increase in malaria and schistosomiasis. These examples demonstrate the need for different sectors to collaborate so as to avoid maladaptation.

Knowledge sharing across regions can be very cost effective. Adaptation strategies obtained from one country may be applicable to other countries in the region. Currently there is little active knowledge sharing arrangements across the regions. It is noteworthy that while there are regional economic blocks such as Common Market for Eastern and Southern Africs (COMESA), Economic Community for West African States (ECOWAS), Southern Africa Development Community (SADAC) there are no common climate adaptation platforms where knowledge can be shared. It is time that regional blocks with similar adaptation challenges should initiate collaboration for more cost effective development of adaptation strategies.

Likewise it is desirable to develop international networks that can mobilize funding for adaptation research and development. Such networks can also marshal the necessary skills that may not be available in a region. Each partner in the network will bring in unique strengths that will synergize the network.

\section{Mobilization of funding}

Research and development requires sustained funding. This is an investment to avoid future damage by the impacts of climate change. African institutions engaged in adaptation in climate change must develop sustainable strategies to cope with a rapidly changing environmental that will largely have a negative impact on human health and wellbeing. The "wait and see", laissez-affaire attitude and "business as usual" approach to adaptation will be ineffective against the forces of climate change. Adaptation to climate change will have to be integrated into development programs and the institution will be required to prioritize their development strategies while taking into account the need to reduce the impacts of climate change.

In many cases national governments require the support of external development partners for budgetary support. In order to determine areas of priority that needs support data is required to provide evidence that sectors are being impacted by climate change and that these impacts need to be addressed and reduced. Research institutions will therefore have to collect the relevant data to show the impacts. It is thus critical that links are developed between research institutions and development partners. In the past research institutions have had very little contact with development partners. Research institutions will need to address transitional research whereby research results are translated directly into utilities relevant to climate change adaptation.

Adaptation will also demand that more basic research is carried out in order to understand more complex phenomenon that affect human health. For example 
how will extreme heat affect learning in African schools where there is no chance of air conditioning? How will malnutrition increase vulnerability to infectious and non-infectious diseases in semiarid areas? Climate change will be associated with complex health impacts that need to be addressed. This area of research is mainly funded by specialized agencies through competitive grants that need highly trained scientists with strong track records. These types of grants require a network of national and foreign institutions that can pool their human and capital resources. National research institutions are encouraged to explore ways of forming partnerships of this kind.

In most African countries there is very little support in terms of research grants from national governments. Even where grants are available the impacts of these grants is not visible. It may be a good idea to channel such funds into a network of junior and more experienced senior scientists in addressing an issue that is relevant to climate change impact in health. For example can environmental intervention reduce malaria $\underline{73}$ in the east African highlands? Non chemical interventions have been developed but they need to be tested and deployed. These are low budget projects that national governments can afford to support. Several private foundations have resources that they could invest in finding solutions to climate change adaptation in Africa, such as support for higher education with reference to climate change. Private foundations in the US invested $\$ 436$ million to address climate change in $2007 \underline{86}$. Foundation giving for climate change has increased nearly 5-fold domestically since 1997 and nearly 8-fold internationally. African research institutions will need to develop strategies for accessing such funding through various mechanisms.

\section{Training}

Climate is a life supporting system that is fundamental to existence. Training and education must take cognizance of climate changes in order to increase skills required for the reduction of vulnerability to impacts from meteorological hazards. Training can occur at primary, secondary and tertiary levels and perhaps even more important at the community level. While training can increase the skill for adaptation, education will increase the public awareness on the hazards, vulnerability and adaptation. In addition various steps in mitigation will have to be undertaken to reduce the drivers of climate change. Failure to increase training and education programs will leave the human populations in a state of vulnerability $\underline{87}$.
Furthermore there is need to increase skills in adaptive capacity in all sectors. It is expected that demand for adaptation skills will increase and these skills could result in migration of highly skilled manpower. There is therefore need to retain these skills in the countries of origin. Incentives must be made available to encourage research into adaptation strategies and technologies. Low human resource capacity increases the vulnerability of the institutional functions to adaptation to climate change.

Acknowledgments: This work was supported by the Climate Change Adaptation Africa, CCAA, Knowledge Sharing, funded by IDRC, Canada and DFID, United Kingdom. I take this opportunity to acknowledge the effort of Dr. Fatima Denton, the project director in conceptualising the analytical framework. The invaluable inputs of many of the CCAA staff in hosting writing workshops in Kenya, Ethiopia, South Africa and Senegal in highly appreciated. I wish to thank Dr. Diana SM Karanja, Daniel S Karanja and Dr. Edna Ototo for their editorial assistance.

\section{REFERENCES}

1. Agrawal A. The role of local institutions in adaptation to climate change. International Forestry Research and Institutions Program (IFRI) Working Paper. 2008(W08I3).

2. Elderd BD, Reilly JR. Warmer temperatures increase disease transmission and outbreak intensity in a hostpathogen system. Journal of Animal Ecology. 2014;83(4):838-849.

3. World Bank. Climate Knowledge Portal, Kenya. Retrieved from

https://climateknowledgeportal.worldbank.org/country/k enya/climate-data-historical. Retrieved on 31.03.2021.

4. African Union. World Malaria Day: "Zero Malaria Starts with Me". Retrieved from https://au.int/en/pressreleases/20190425/world-malariaday-zero-malaria-starts-me. Retrieved on 31.03.2021; 2019.

5. Abeku TAJEid. Response to malaria epidemics in Africa. 2007;13(5):681.

6. Abeku TA, Hay SI, Ochola S, et al. Malaria epidemic early warning and detection in African highlands. Trends Parasitol. 2004;20(9):400-405.

7. Githeko AK, Ogallo L, Lemnge M, Okia M, Ototo EN. Development and validation of climate and ecosystembased early malaria epidemic prediction models in East Africa. Malaria journal. 2014;13(1):329.

8. Kiszewski AE, Teklehaimanot A. A review of the clinical and epidemiologic burdens of epidemic malaria. The American journal of tropical medicine and hygiene. 2004;71(2):128.

9. Githeko AK. Malaria and climate change. Commonwealth Health Ministers' Update 2009. 2009:42-45.

10. Chen H, Githeko AK, Zhou G, Githure JI, Yan G. New records of Anopheles arabiensis breeding on the Mount 
Kenya highlands indicate indigenous malaria transmission. Malaria Journal. 2006;5(1):17.

11. Omumbo JA, Lyon B, Waweru SM, Connor SJ, Thomson MC. Raised temperatures over the Kericho tea estates: revisiting the climate in the East African highlands malaria debate. Malaria Journal. 2011;10(1):12

12. WHO. World malaria report 2019. Retrieved from https://www.who.int/publications/i/item/978924156572 1. Retrieved on 31.03.20212019.

13. Ototo EN, Zhou G, Kamau L, et al. Age-specific Plasmodium parasite profile in pre and post ITN intervention period at a highland site in western Kenya. Malaria journal. 2017;16(1):466.

14. Davies FG. The historical and recent impact of Rift Valley fever in Africa. American Journal of Tropical Medicine. August 2010;83(2):73-74.

15. Meegan JM. The Rift Valley fever epizootic in Egypt 197778. 1. Description of the epizzotic and virological studies Trans R Soc Trop Med Hyg. 1979;73(6):618-623.

16. Woods CW, Karpati AM, Grein T, et al. An outbreak of Rift Valley fever in Northeastern Kenya, 1997-98. Emerg Infect Dis. . February 2002;8(2):138-144.

17. Pagès F, Peyrefitte $\mathrm{CN}$, Mve MT, et al. Aedes albopictus mosquito: the main vector of the 2007 Chikungunya outbreak in Gabon. PLoS One. 2009;4(3):e4691.

18. LaBeaud AD, Sutherland LJ, Muiruri S, et al. Arbovirus prevalence in mosquitoes, kenya. Emerging Infectious Diseases. $2011 ; 17(2): 233$.

19. Anyamba A, Jean-Paul C, Compton T, Kenneth L. Developing global climate anomalies suggest potential disease risks for 2006-2007. International Journal of Health Geographics. 2006;5.

20. Murithi RM, Munyua P, Ithondeka PM, et al. Rift Valley fever in Kenya: history of epizootics and identification of vulnerable districts. Epidemiology and infection. 2011;139(03):372-380.

21. Wanyoike F, Mtimet N, Bett BJPvm. Willingness to pay for a Rift valley fever (RVF) vaccine among Kenyan cattle producers. 2019;171:104763.

22. WHO. Yellow fever : a current threat. Retrieved from https://www.who.int/csr/disease/yellowfev/impactl/en/. Retrieved on 31.03 .2021

23. Hamlet A, Jean K, Perea W, et al. The seasonal influence of climate and environment on yellow fever transmission across Africa. 2018;12(3):e0006284.

24. Gaythorpe KA, Hamlet A, Cibrelus L, Garske T, Ferguson NM. The effect of climate change on yellow fever disease burden in Africa. Elife. 2020;9:e55619.

25. Gattas N, Kaganov Y, Rimon DJH. Many faces of West Nile fever--the first case of West Nile fever in the western Galilee, Israel. 2001;140(8):686.

26. Rossi SL, Ross TM, Evans JD. West Nile virus. Clinics in laboratory medicine. 2010;30(1):47-65.
27. Sule WF, Oluwayelu DO, Hernández-Triana LM, et al. Epidemiology and ecology of West Nile virus in subSaharan Africa. 2018;11(1):414.

28. Weaver SC, Lecuit M. Chikungunya virus and the global spread of a mosquito-borne disease. New England Journal of Medicine. 2015:372(13):1231-1239.

29. Kelvin AA. Outbreak of Chikungunya in the Republic of Congo and the global picture. The Journal of Infection in Developing Countries. 2011;5(06):441-444.

30. Caglioti C, Lalle E, Castilletti C, Carletti F, Capobianchi MR, Bordi LJNM. Chikungunya virus infection: an overview. 2013;36(3):211-227.

31. Mease LE, Coldren RL, Musila LA, et al. Seroprevalence and distribution of arboviral infections among rural Kenyan adults: A cross-sectional study. Virology Journal. $2011 ; 8(1): 371$

32. Renault P, Solet J-L, Sissoko D, et al. A major epidemic of chikungunya virus infection on Reunion Island, France, 2005-2006. 2007;77(4):727-731

33. Stolerman LM, Maia PD, Kutz JNJPo. Forecasting dengue fever in Brazil: An assessment of climate conditions. 2019;14(8):e0220106

34. Amarasinghe A, Kuritsky JN, Letson GW, Margolis HS Dengue virus infection in Africa. Emerg Infect Dis. 2011;17:1349-1354.

35. Moraes BCd, Souza EBd, Sodré GRC, Ferreira DBdS, Ribeiro JBMJCdSP. Sazonalidade nas notificações de dengue das capitais da Amazônia e os impactos do El Niño/La Niña. 2019;35:e00123417.

36. Sippy R, Herrera D, Gaus D, Gangnon RE, Patz JA, Osorio JEJPntd. Seasonal patterns of dengue fever in rural Ecuador: 2009-2016. 2019;13(5):e0007360.

37. Githeko AK, Ndegwa W. Predicting malaria epidemics in the Kenyan highlands using climate data: a tool for decision makers. Global change and human health. 2001;2(1):54-63.

38. Olago D, Marshall $M$, Wandiga SO. Climatic, socioeconomic, and health factors affecting human vulnerability to cholera in the Lake Victoria basin, East Africa. Ambio. 2007:350-358.

39. Gaffga NH, Tauxe RV, Mintz ED. Cholera: a new homeland in Africa? The American journal of tropical medicine and hygiene. 2007:77(4):705-713.

40. Kebede S, Duale S, Yokouide A, Alemu W. Trends of major disease outbreaks in the African region, 2003-2007. East African Journal of Public Health. 2010;7(1).

41. Paz S. Impact of Temperature Variability on Cholera Incidence in Southeastern Africa, 197-2006. Ecohealth. $2009 ; 6(3): 340-345$

42. Reyburn R, Kim DR, Emch M, Khatib A, von Seidlein L, Ali M. Climate variability and the outbreaks of cholera in Zanzibar, east Africa: a time series analysis. The American journal of tropical medicine and hygiene. 2011;84(6):862.

43. Emch M, Caryl F, Sirajul IM, Mohammad A. Seasonality of cholera from 1974 to 2005: a review of global patterns. Int $J$ Health Geogr. 2008;7:31. 
44. Olago D, Marshall M, Wandiga SO, et al. Climatic, socioeconomic, and health factors affecting human vulnerability to cholera in the Lake Victoria basin, East Africa. AMBIO: A Journal of the Human Environment. $2007 ; 36(4): 350-358$.

45. Feikin DR, Tabu CW, Gichuki J. Does water hyacinth on East African lakes promote cholera outbreaks? The American journal of tropical medicine and hygiene. $2010 ; 83(2): 370-373$.

46. Moore SM, Azman AS, Zaitchik BF, et al. El Niño and the shifting geography of cholera in Africa. 2017;114(17):4436-4441.

47. Youssouf H, Subiros M, Dennetiere G, et al. Rift Valley Fever Outbreak, Mayotte, France, 2018-2019. Emerging infectious diseases. 2020;26(4):769.

48. Kelly-Hope LA, Alonso WJ, Thiem VD, et al. Temporal trends and climatic factors associated with bacterial enteric diseases in Vietnam, 1991â€“2001. Environmental Health Perspectives. 2008;116(1):7.

49. Desenclos JC, Zergabachew A, Desmoulins B, Chouteau L, Desve G, Admassu M. Clinical, microbiological and antibiotic susceptibility patterns of diarrhoea in Korem, Ethiopia. 1988.

50. WHO. Vaccine research. Retrieved from WHO. Vaccine research. Retrieved from l/en/index7.html. Retrieved on 31.03.2021.

51. Crump JA, Luby SP, Mintz ED. The global burden of typhoid fever. Bulletin of the World Health Organization. 2004;82(5):346-353.

52. Mor SM, Tzipori S. Cryptosporidiosis in children in subSaharan Africa: a lingering challenge. Clinical infectious diseases. 2008;47(7):915.

53. Chao DL, Roose A, Roh M, Kotloff KL, Proctor JLJPntd The seasonality of diarrheal pathogens: A retrospective study of seven sites over three years. 2019:13(8):e0007211

54. Heaney AK, Shaman J, Alexander KAJNc. El NiñoSouthern oscillation and under-5 diarrhea in Botswana. $2019 ; 10(1): 1-9$

55. Watts N, Amann M, Arnell N, et al. The 2020 report of The Lancet Countdown on health and climate change: responding to converging crises. The Lancet. 2020.

56. UNICEF. The State of the World's Children 2019 https://www.unicef.org/reports/state-of-worlds-children2019.

57. Population Reference B. 2006 World Population Data Sheet of the Population Reference Bureau: Population Reference Bureau; 2006.

58. McMichael AJ, Haines A. Global climate change: the potential effects on health. BMJ. 1997;315(7111):805809.

59. Bhutta ZA, Ahmed T, Black RE, et al. What works? Interventions for maternal and child undernutrition and survival. The Lancet. 2008:371(9610):417-440.
60. Victora CG, Adair L, Fall C, et al. Maternal and child undernutrition: consequences for adult health and human capital. The lancet. 2008;371(9609):340-357.

61. Rupa B, Samet JM. Relation between elevated ambient temperature and mortality: a review of the epidemiologic evidence. Epidemiologic reviews. 2002;24(2):190-202.

62. Kynast-Wolf G, Preuß M, Sié A, Kouyaté B, Becher H. Seasonal patterns of cardiovascular disease mortality of adults in Burkina Faso, West Africa. Tropical Medicine $\mathcal{E}$ International Health. 2010;15(9):1082-1089.

63. Lapeyssonnie L. Comparative epidemiologic study of meningococcic cerebrospinal meningitis in temperate regions and in the meningitis belt in Africa. Attempt at synthesis]. Medecine tropicale: revue du Corps de sante colonial. 1968:28(6):709.

64. Yaka P, Sultan B, Broutin H, Janicot S, Philippon S, Fourquet N. International Journal of Health Geographics. International Journal of Health Geographics. 2008;7:34.

65. Chippaux JP. Control of meningococcal meningitis outbreaks in sub-Saharan Africa. The Journal of Infection in Developing Countries. 2008;2(05):335-345.

66. Harrison LH, Trotter CL, Ramsay ME. Global epidemiology of meningococcal disease. Vaccine. 2009;27:B51-B63.

67. Choudhuri D, Huda T, Theodoratou E, et al. An evaluation of emerging vaccines for childhood meningococcal disease. BMC Public Health. 2011;11(Suppl 3):S29.

68. Bezirtzoglou C, Dekas K, Charvalos E. Climate changes, environment and infection: facts, scenarios and growing awareness from the public health community within Europe. Anaerobe. Dec 2011;17(6):337-340.

69. $\mathrm{Hu} \mathrm{X}, \mathrm{Xu} \mathrm{H}$. A new remote sensing index based on the pressure-state-response framework to assess regional ecological change. Environmental Science and Pollution Research. 2019;26(6):5381-5393

70. Githeko AK, Ndegwa W. Predicting malaria epidemics in the Kenyan highlands using climate data: a tool for decision makers. Global change \& human health. 2001:2(1):54-63.

71. WHO. Priority-setting for national health policies, strategies and plans. Geneva, Switzerland; 2016.

72. Mouchet J, Manguin S, Sircoulon J, et al. Evolution of malaria in Africa for the past 40 years: impact of climatic and human factors. Journal of the American Mosquito Control Association. 1998;14(2):121.

73. Wamae PM, Githeko AK, Menya DM, Takken W. Shading by Napier Grass Reduces Malaria Vector Larvae in Natural Habitats in Western Kenya Highlands. EcoHealth. 2010:113

74. Githeko AK. Malaria and climate change: special feature. IDRC.

75. Hay SI, Cox J, Rogers DJ, et al. Climate change and the resurgence of malaria in the East African bighlands. Nature. Feb 21 2002;415(6874):905-909.

76. Pascual M, Cazelles B, Bouma M, Chaves L, Koelle KJPotRSBBS. Shifting patterns: malaria dynamics and 
rainfall variability in an African highland. 2008;275(1631):123-132.

77. Alonso D, Bouma MJ, Pascual M. Epidemic malaria and warmer temperatures in recent decades in an East African highland. Proceedings of the Royal Society of London B: Biological Sciences. 2011;278(1712):1661-1669.

78. NIH. Climate Change and Health: Assessing and Modeling Population Vulnerability to Climate Change (R21). Retrieved from https://grants.nih.gov/grants/guide/pafiles/PAR-10-235.html\#PartII. Retrieved on 31.03.2021.

79. Bank W. Climate Change. Retrieved from https://www.worldbank.org/en/topic/climatechange. Retrieved on 31.03.2021.

80. AFDB. Health. Retrieved from https://www.afdb.org/en/topics-andsectors/sectors/health. Retrieved on 31.03.2021.

81. WHO. Climate change and health, Retrieved from https://www.who.int/en/news-room/factsheets/detail/climate-change-and-health. Retrieved on 31.03 .2021

82. Open Society Foundations. Higher Education. Retrieved from https://www.opensocietyfoundations.org/what-wedo/themes/higher-education. Retrieved on 31.03.2021.

83. Aishwarya M. Leadership Styles in Management, Business Management. Retrieved from https://www.businessmanagementideas.com/manageme nt/leadership-styles/leadership-styles-in-managementbusiness-management/18457. Retrieved on 31.03.2021.

84. Wanjala CL, Waitumbi J, Zhou G, Githeko AK. Identification of malaria transmission and epidemic hotspots in the Western Kenya highlands: its application to malaria epidemic prediction. Parasites \& Vectors. $2011 ; 4(1): 81$.

85. Atieli H, Menya D, Githeko A, Scott T. House design modifications reduce indoor resting malaria vector densities in rice irrigation scheme area in western Kenya. Malaria Journal. 2009:8(1):108.

86. Morena E. Climate Philanthropy: The Tyranny of the 2 Percent. Retrieved from https://philanthropynewsdigest.org/columns/alliancepnd/climate-philanthropy-the-tyranny-of-the-2-percent. Retrieved on 31.03.2021.

87. Parry ML. Climate Change 2007: impacts, adaptation and vulnerability: contribution of Working Group II to the fourth assessment report of the Intergovernmental Panel on Climate Change: Cambridge Univ Pr; 2007.

Peer Reviewed

Competing Interests: None declared.

Received: 12/31/2020; Accepted: 4/7/2021

Cite this article as: Githeko AK. Health related vulnerabilities and enabling institutions to facilitate responses to climate change in East Africa. E Afr Sci. 2021;3(1):1-18. http://doi.org/10.24248/EASciD-21-00001

(- Githeko. This is an open-access article distributed under the terms of the Creative Commons Attribution License, which permits unrestricted use, distribution, and reproduction in any medium, provided the original author and source are properly cited. To view a copy of the license, visit http://creativecommons.org/licens- es/by/4.0/. When linking to this article, please use the following permanent link: http://doi.org/10.24248/EASCi-D-21-00001 